OPEN

SUBJECT AREAS:

CHEMISTRY

COMPUTATIONAL CHEMISTRY

ORGANIC CHEMISTRY

SYNTHESIS

Received

24 May 2011

Accepted

12 August 2011

Published

5 September 2011

Correspondence and requests for materials should be addressed to T.H. (thosoya.cb@tmd. ac.jp)

\section{Enhanced clickability of doubly sterically-hindered aryl azides}

\author{
Suguru Yoshida' ${ }^{1}$ Akira Shiraishi ${ }^{2}$, Kimiyuki Kanno ${ }^{2}$, Takeshi Matsushita ${ }^{3}$, Kohei Johmoto ${ }^{4}$, \\ Hidehiro Uekusa ${ }^{4}$ \& Takamitsu Hosoya ${ }^{1,2}$
}

'Laboratory of Chemical Biology, Graduate School of Biomedical Science, Institute of Biomaterials and Bioengineering, Tokyo Medical and Dental University, 2-3-10 Kanda-Surugadai, Chiyoda-ku, Tokyo 101-0062, Japan, ${ }^{2}$ Department of Biological Information, Graduate School of Bioscience and Biotechnology, Tokyo Institute of Technology, 4259 Nagatsuta-cho, Midori-ku, Yokohama 226-8501, Japan, ${ }^{3}$ Goi Research Center, Chisso Petrochemical Corporation, 5-1 Goikaigan, Ichihara, Chiba 2908551 , Japan, ${ }^{4}$ Department of Chemistry and Materials Science, Graduate School of Science and Engineering, Tokyo Institute of Technology, 2-12-1 Ookayama, Meguro-ku, Tokyo, 152-8551, Japan.

Steric character is one of the most fundamental factors to determine the reactivity of the substrate in organic synthesis. In bimolecular reaction, the sterically-bulky group situated close to the reactive center generally prevents the approach of the reaction partner retarding the bond formation. This report describes, to the contrary, significantly enhanced reactivity of 2,6-disubstituted phenyl azides observed in catalyst-free 1,3-dipolar cycloaddition with alkynes, unexpectedly reacting faster than unsubstituted phenyl azide and even more faster than unhindered alkyl azide, despite the steric hindrance adjacent to the reactive azido group. Experimental and computational studies have indicated that the steric hindrance eliciting the inhibition of resonance between azido group and the aromatic ring is the primary cause of this apparently-paradoxical phenomenon. This is the first type of steric acceleration, indicating a possibility of designing a highly reactive functional group by strategically locating it in the sterically-congested environment.

\footnotetext{
lick reaction, epitomized by copper(I)-catalyzed azide-alkyne cycloaddition, has become one of the most reliable methods to connect molecules covalently in broad disciplines including materials chemistry and chemical biology. ${ }^{1-5}$ In particular, strain-promoted click reaction, a copper-free variant exploiting a cyclooctyne derivative that reacts spontaneously with an azide, has realized harmless chemical modification of biomolecules in cultured cells and in living animals. ${ }^{6-15}$ Recently, we have developed the "double-click" reaction to conjugate conveniently an azido-biomolecule with a small azido compound using Sondheimer diyne $(1)^{16}$ as a bis-dipolarophile (Fig. 1a) ${ }^{17}$ In this reaction, an efficient assembly of two azides takes place by virtue of the two highly strained triple bonds of 1 providing bis-cycloadduct in high yield. The practical utility of the double-click strategy has been demonstrated by efficient labeling of azido-glycoconjugates on the cell surface as well as an azido-installed recombinant protein with a fluorescein-conjugated azide. While the double-click technique has been shown comparable in labeling efficiency to the single-click procedure, experimental and computational studies presented that the monoyne intermediate, considered as the initial cycloadduct of this reaction, is remarkably reactive than the starting diyne 1 , which might pose an insufficient conjugation.

To make the double-click conjugation system more efficient, we have conceived the idea of performing a sequential double-click reaction ${ }^{18}$ using diazidobenzene derivative 2 , which bears two sterically-differentiated azido groups, with an anticipation to connect first alkyne at the less hindered side and then the second alkyne at the remaining sterically-hindered side (Fig. 1b). Contrary to our expectations, however, the click reaction of diazide 2 with strained alkyne 3 a proceeded predominantly at the sterically-hindered side furnishing $4 \mathbf{b}$ in high yield (Fig. 1c, see Supplementary Information). This unexpected but very intriguing result prompted us to elucidate the origin of enhanced reactivity of sterically-hindered azido group.
}

\section{Results}

The distinguished reactivity of sterically-hindered aryl azide was demonstrated through the study on the substrate scope of the azide in double-click reaction with diyne 1. First, we compared the reactivities of two typical sterically-hindered azides, 1-adamantyl azide (5b) and 2,6-diisopropylphenyl azide (5c), with unhindered benzyl azide (5a) by monitoring the reaction with 1 in methanol- $d_{4}$ by ${ }^{1} \mathrm{H}$ NMR spectroscopy. As a result, while the reaction of $\mathbf{1}$ with bulky $\mathbf{5 b}$ was retarded drastically ( $18 \%$ yield of bis-cycloadducts at $4 \mathrm{~h}$ ) compared to that with 
a
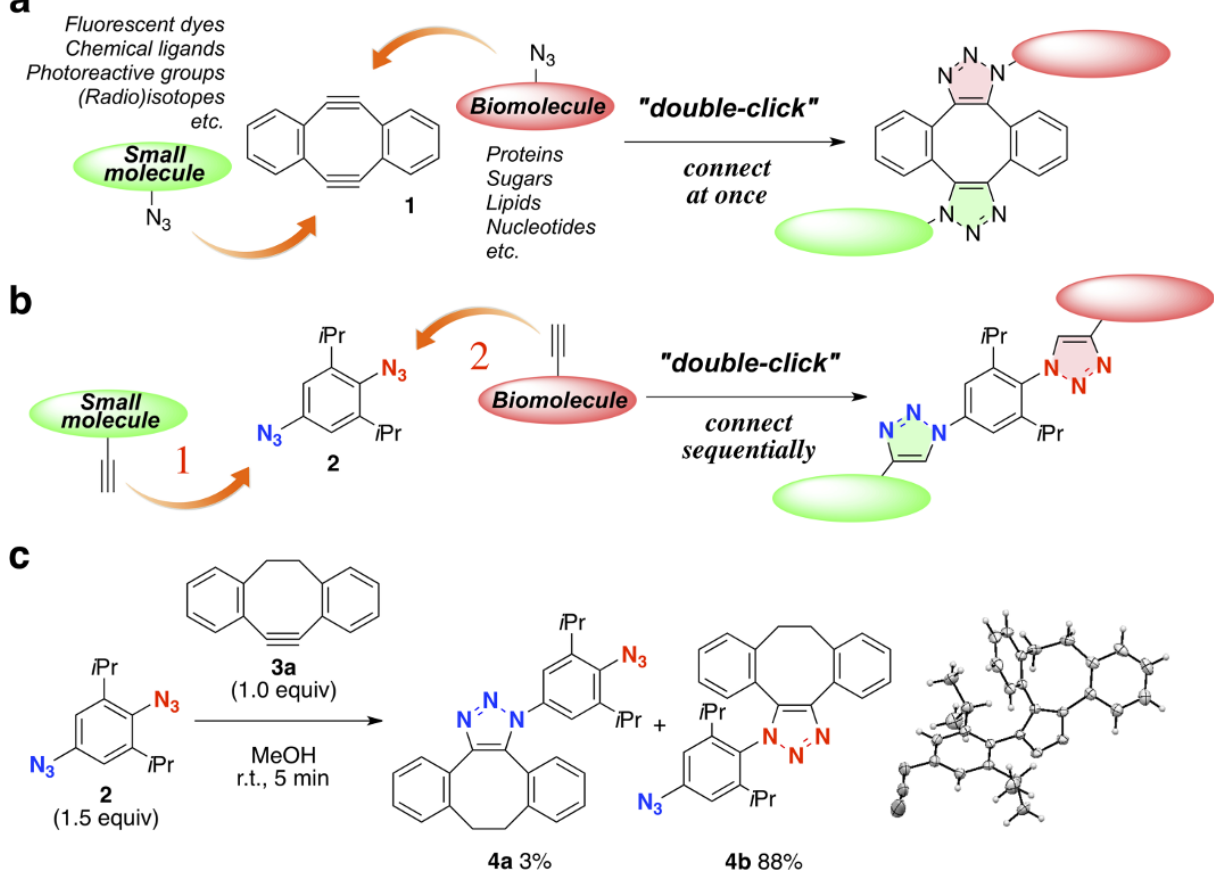

Figure $1 \mid$ Double-click reactions using a bis-reactive compound for efficient assembly of molecules. (a) The double-click method for convenient conjugation of an azido-biomolecule with a small azido compound mediated by the Sondheimer diyne (1). (b) An initial plan of sequential double-click conjugation by diazidobenzene derivative 2 bearing two sterically-differentiated azido groups. We envisaged that the first cycloaddition with an alkyne would proceed at the less hindered side and the remaining sterically-hindered azido group could be used for the second cycloaddition with another alkyne. (c) Click reaction of diazide $\mathbf{2}$ with strained alkyne $\mathbf{3 a}$ unexpectedly affording $\mathbf{4} \mathbf{b}$ as the major product. This result indicated that the reaction occurred predominantly at the more sterically-hindered azido group of $\mathbf{2}$. The regiochemistry of $\mathbf{4} \mathbf{b}$ was unequivocally determined by X-ray structure analysis (CCDC 810844).

benzyl azide (5a) (87\%, $30 \mathrm{~min})$, the reaction with $5 \mathrm{c}$ was rather hastened under the same conditions affording the product quantitatively within $5 \mathrm{~min}$ (see Supplementary Information). To our surprise, the second-order rate constant $(k)$ for the reaction of 1 with $5 \mathrm{c}$ in methanol at $25^{\circ} \mathrm{C}\left(k=6.7 \times 10^{-1} \mathrm{M}^{-1} \mathrm{~s}^{-1}\right)$ was ten times as large as that for $5 \mathrm{a}\left(k=6.3 \times 10^{-2} \mathrm{M}^{-1} \mathrm{~s}^{-1}\right) .{ }^{17}$

Exploring further the double-click reaction with a focus on the substituent effect of aryl azides more clearly showed that the bulkiness around the azido group is the key factor to enhance the reaction rate (Fig. 2, Table 1). Although all of the reactions of diyne 1 with various aryl azides $\mathbf{5} \mathbf{d}-\mathbf{5} \mathbf{j}$ afforded a regioisomeric mixture of biscycloadducts in an excellent yield, the reaction rates varied greatly depending on the substrate. Notably, the reaction with unsubstituted phenyl azide (5d) proceeded about seven times slower than $5 \mathbf{a}$ and, more importantly, 76 times slower than $5 \mathrm{c}$ (entry 1 vs 8 , Table 1 ). para-Methoxy and para-trifluoromethyl groups showed only limited effects (entries 2 and 3, Table 1), indicating that the electronic nature of the substituent is not a decisive factor to affect the reaction rate. The reactivity of mono-ortho-substituted phenyl azides was neither

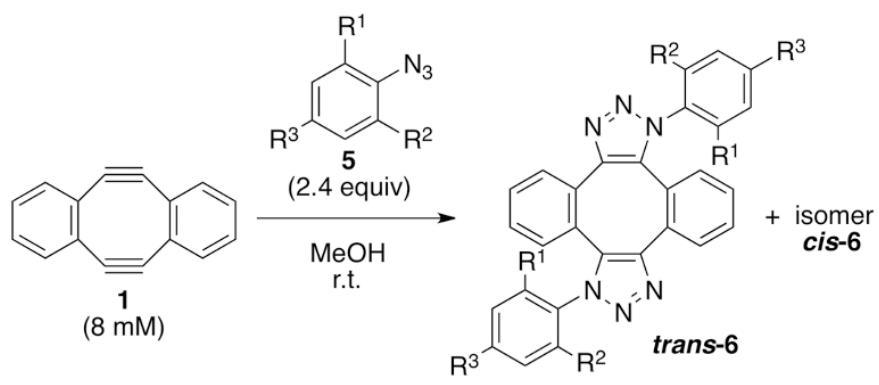

Figure $2 \mid$ Reaction scheme for Table 1. The double-click reaction of Sondheimer diyne (1) with various aryl azides $\mathbf{5}$ was examined. enhanced nor diminished to a large extent (entries 4 and 5, Table 1). In contrast, the reactions with 2,6-disubstituted phenyl azides were dramatically accelerated, as the size of substituents became bulkier (entries 6-8, Table 1).

A valuable hint to understand the role of bulky substituents in enhancing the reactivity of sterically-surrounded azido group was provided from UV absorption spectra of the azides (Fig. 3a). The intensity of the peak at long-wavelength region observed for $5 \mathbf{d}$ $\left(\lambda_{\max }=248 \mathrm{~nm}\right)$ decreased considerably in $\mathbf{5 c}$, suggesting that the conjugated state of the azido group with the aromatic ring between these azides differs substantially. The stationary structure of azides at the ground state optimized by a density functional theory (DFT) (B3LYP/6-31G(d)) method $^{19}$ supported this implication indicating that the azido group of $5 \mathrm{~d}$ lies coplanar with the benzene ring, while that of $5 c$ is largely twisted out of the plane, forced by the bulky

Table 1 | Double-click reaction of diyne $\mathbf{1}$ and aryl azide $\mathbf{5}$.

\begin{tabular}{|c|c|c|c|c|c|c|c|c|}
\hline Entry & 5 & $\mathrm{R}^{1}$ & $\mathrm{R}^{2}$ & $\mathrm{R}^{3}$ & 6 & $\begin{array}{l}\text { Yield }(\%)^{*} \\
\text { (trans/cis) }^{\dagger}\end{array}$ & $k\left(M^{-1} s^{-1}\right)$ & $k_{\text {rel }}$ \\
\hline $\begin{array}{l}2 \\
3 \\
4 \\
5\end{array}$ & $\begin{array}{l}5 \mathbf{5} \\
\mathbf{5 g} \\
\mathbf{5 h} \\
\mathbf{5 i} \\
\mathbf{5 i}\end{array}$ & $\begin{array}{c}\mathrm{H} \\
\mathrm{H} \\
\mathrm{H} \\
\mathrm{Me} \\
\mathrm{iPr} \\
\mathrm{Me} \\
\mathrm{Et} \\
\mathrm{iPr}\end{array}$ & $\begin{array}{c}\mathrm{H} \\
\mathrm{H} \\
\mathrm{H} \\
\mathrm{H} \\
\mathrm{H} \\
\mathrm{Me} \\
\mathrm{Et} \\
\mathrm{iPr}\end{array}$ & $\begin{array}{l}\mathrm{H} \\
\mathrm{OMe}^{-} \\
\mathrm{CF}_{3} \\
\mathrm{H} \\
\mathrm{H} \\
\mathrm{H} \\
\mathrm{H} \\
\mathrm{H}\end{array}$ & $\begin{array}{l}\text { 6d } \\
6 e \\
6 f \\
6 g \\
6 h \\
6 i \\
6 j \\
6 c\end{array}$ & $\begin{array}{l}94(43 / 57)^{5} \\
89(36 / 64) \\
97(50 / 50) \\
98(52 / 48) \\
95(60 / 40) \\
92(64 / 36) \\
93(73 / 27) \\
95(96 / 4)\end{array}$ & $\begin{array}{l}8.8 \times 10^{-3} \\
3.3 \times 10^{-2} \\
7.9 \times 10^{-3} \\
1.2 \times 10^{-2} \\
8.9 \times 10^{-3} \\
3.2 \times 10^{-1} \\
3.8 \times 10^{-1} \\
6.7 \times 10^{-1}\end{array}$ & $\begin{array}{l}1 \\
3.8 \\
0.9 \\
1.4 \\
1.0 \\
36 \\
43 \\
76\end{array}$ \\
\hline \multicolumn{9}{|c|}{$\begin{array}{l}\text { "Isolated yield as a mixture of regioisomers. } \\
\text { "Ratio was determined based on 'H NMR analysis of isolated regioisomeric mixture. } \\
\text { Stereochemistry of } \mathbf{6} \text { was unequivocally determined by X-ray analysis of purified regioisomer } \\
\text { (CCDC } 810837-810843 \text { for cis-6b, } \mathbf{6 c}, \mathbf{6 e}, \mathbf{6 9}, \mathbf{6 h}, \mathbf{6 i}, \mathbf{6 j} \text { and } 810930-810936 \text { for } \\
\text { corresponding trans-isomers) except } \mathbf{6 f} \text {. } \\
\text { "Data from ref. } 17 \text {. }\end{array}$} \\
\hline
\end{tabular}


substituents at both ortho-positions (Fig. 3c). The calculation of rotation energy of the azido group also exhibited that $5 \mathrm{~d}$ takes predominantly the highly-conjugated structure, showing a sharp contrast with $5 \mathrm{c}$, which rather prefers the markedly-twisted conformation (Fig. 3b). Interestingly, the rotational barrier of the sterically-hindered azido group of $5 \mathrm{c}$ was significantly lower than that of $5 \mathrm{~d}$. These data have implied that the reactivity enhancement could be attributed to the inhibition of resonance ${ }^{20}$ between the aromatic ring and the azido group lowering its motional energy.

To gain a mechanistic insight, we initially calculated and compared the frontier molecular orbitals ${ }^{21}$ of $1,5 \mathrm{c}$, and $5 \mathrm{~d}$, which, however, did not afford a reasonable explanation (see Supplementary Information). Fortunately, instead, the distortion/interaction model, a generalized theory for 1,3-dipolar cycloadditions recently proposed by Houk and coworkers, ${ }^{22,23}$ led us to a comprehensive understanding. They elegantly explained the enhanced clickability of strained cycloalkynes by dividing the activation energy into distortion and interaction energies, demonstrating that the energy required to distort the 1,3-dipole and dipolarophile into their transition-state geometries is the crucial factor as well as the frontier molecular orbital interaction energy. To apply this theory, the transition state (TS) structures for the first cycloaddition of $\mathbf{1}$ with $\mathbf{5 d}$ and $5 \mathrm{c}$, TS-d1 and TS-c1, were also obtained at the same level of the theory (Fig. 3d). The activation energy for the reaction of 1 with $5 \mathrm{c}$ was estimated to be $2.5 \mathrm{kcal} \mathrm{mol}^{-1}$ lower than that with $5 \mathrm{~d}$, providing a good agreement with the experimental result (Fig. 3e). The difference in distortion energies, unexpectedly, was almost equal to that of the activation energies indicating that there is little difference in interaction energies, which must include the factor of steric repulsion arising between the reactants. Considering that the difference in individual distortion energy of diyne 1 between each reaction was comparatively smaller $\left(0.4 \mathrm{kcal} \mathrm{mol}^{-1}\right)$ than that between azides $\left(2.3 \mathrm{kcal} \mathrm{mol}^{-1}\right)$, the enhanced reactivity of $5 c$ can be mostly attributed to its decreased distortion energy compared with $\mathbf{5 d}$.

The generality on the higher reactivity of bulky $5 c$ over unhindered 5d was easily examined by reacting them with other simple alkynes. As a result, not only strained cyclooctyne derivative $3 \mathrm{a}$ but also unstrained alkyne such as dimethyl acetylenedicarboxylate (3b), under the Huisgen reaction conditions, ${ }^{24}$ predominantly afforded $5 c$ derived cycloadducts in the reaction with an equimolar mixture of $5 \mathrm{c}$ and $5 \mathrm{~d}$, clearly demonstrating the prominent clickability of doubly sterically-hindered aryl azides despite the steric barrier (Fig. 4a). On the other hand, an inverted selectivity was observed in the reaction of aryl azides with an acetylide (Fig. $4 \mathrm{~b}$ ). ${ }^{25}$ The preferred formation of 5d-derived triazole $\mathbf{8 d c}$ agrees well with the proposed stepwise mechanism, which should be disadvantageous for hindered substrates.

\section{Discussion}

We have unexpectedly found that sterically-congested azido group of 2,6-disubstituted phenyl azides, despite the steric hindrance, reacts significantly faster than unsubstituted phenyl azide, as well as unhindered alkyl azide in catalyst-free 1,3-dipolar cycloaddition with an alkyne. Although a similar trend was previously reported in iron-catalyzed hydrogenation of sterically-hindered aryl azides, no mechanistic explanation has been given so far. ${ }^{26}$ Our studies on substrate scope and computations have clearly shown that the enhanced reactivity of 2,6-disubstituted phenyl azides can be attributed to the increased distortability of the azido group elicited by the inhibition of resonance with the aromatic ring. The slower reaction observed for benzyl azide (5a) than 2,6-disubstituted phenyl azides can be reasonably explained by taking the contribution of the hyperconjugation between azido group and the hydrogen of alkyl chain into account. Indeed, the calculated distortion and activation energies of methyl azide in the cycloaddition with diyne $\mathbf{1}$ are also larger a
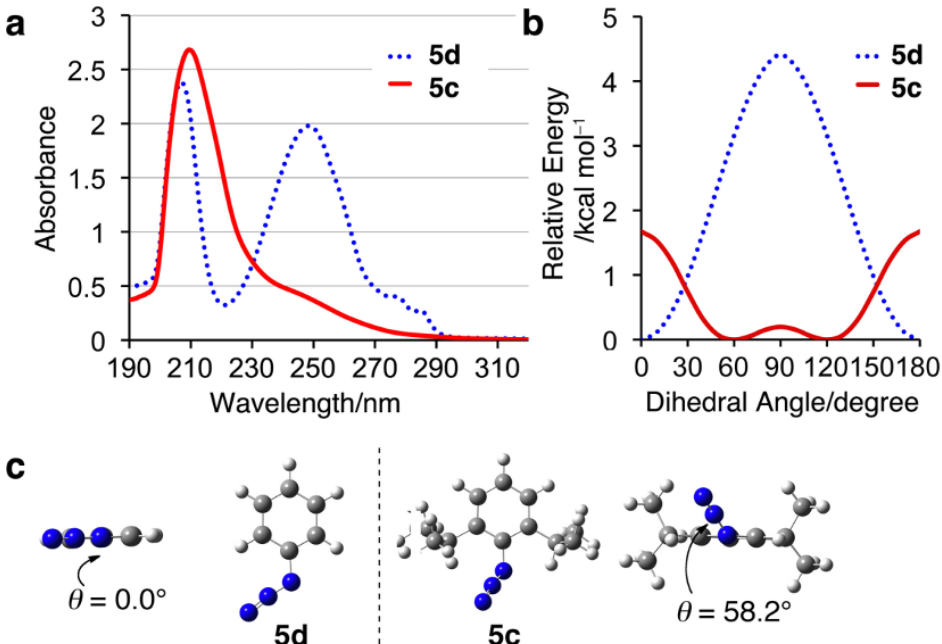

d

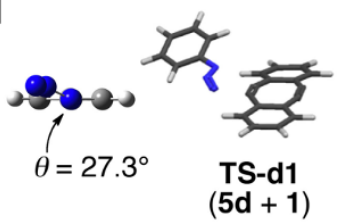

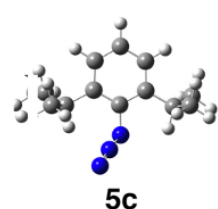
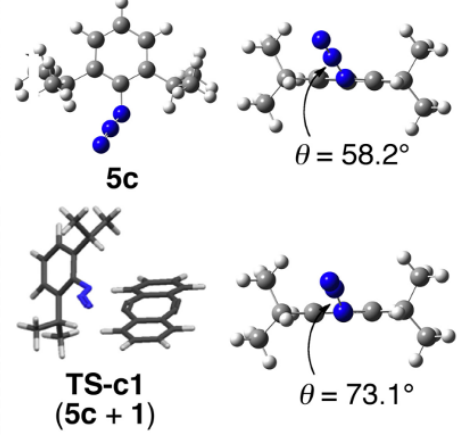

e

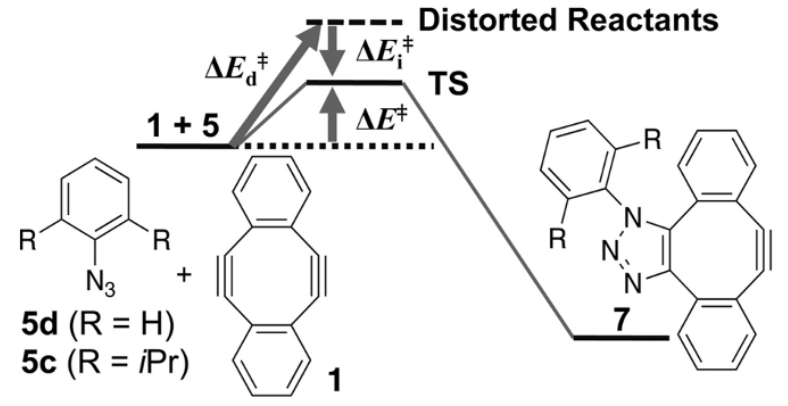

\begin{tabular}{ccc}
\hline Reactants & $\mathbf{5 d}+\mathbf{1}$ & $\mathbf{5 c}+\mathbf{1}$ \\
\hline Product & $\mathbf{7 d}$ & $\mathbf{7 c}$ \\
\hline Distorted reactants & $+17.4 \quad+3.1$ & +15.1 \\
Distortion energy & +2.7 \\
Interaction energy $^{\dagger}\left(\Delta E_{\mathrm{d}}^{\ddagger}\right)$ & +20.4 & +17.8 \\
Activation energy $^{\S}\left(\Delta E^{\ddagger}\right)$ & -9.0 & -8.9 \\
\hline
\end{tabular}

Figure 3 Twisted-conformation of 2,6-diisopropylphenyl azide (5c) enhancing its clickability. (a) Absorption spectra of 5d and 5c in MeOH

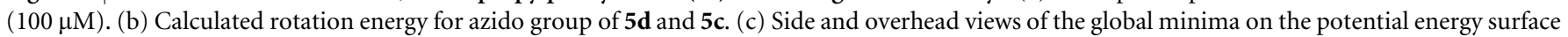

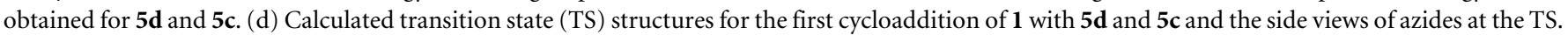

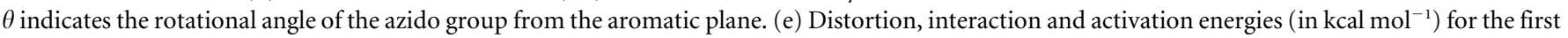

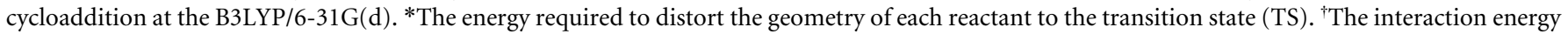

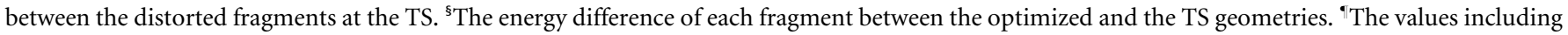

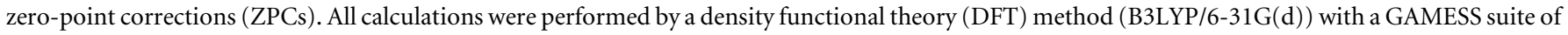
program codes on a TSUBAME 2.0 system at Tokyo Institute of Technology. 


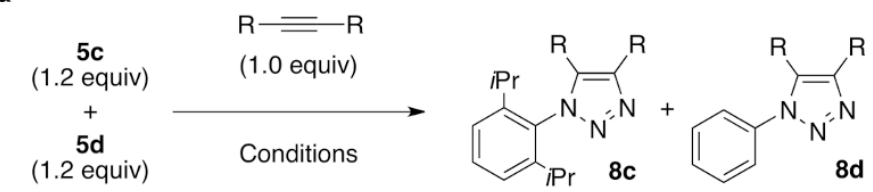

3a $\begin{gathered}\mathrm{MeOH} \\ \text { r.t., } 5 \mathrm{~min}\end{gathered} \quad \mathbf{8 c a} 93 \%+8$ da $7 \%$

b

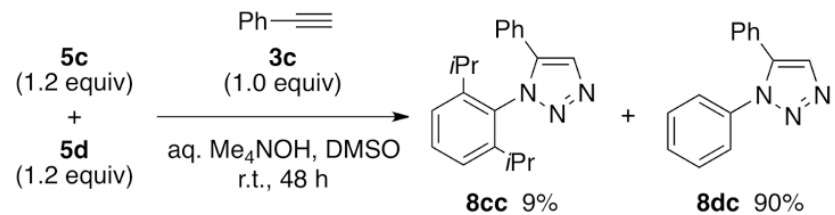

Figure $4 \mid$ Competition between doubly sterically-hindered azide 5c and unhindered azide $5 \mathrm{~d}$ in the reaction with various alkynes. (a) Competition between $\mathbf{5 c}$ and $\mathbf{5 d}$ in the cycloaddition reaction with alkyne 3. (b) Competition between $\mathbf{5 c}$ and $\mathbf{5 d}$ in the reaction with acetylide generated in situ. Yields were determined based on ${ }^{1} \mathrm{H}$ NMR analysis.

than those of $5 c{ }^{17}$ All of these results suggest that the extended conjugation containing azido group makes it hard to deform to the TS structure, thus decreasing the reactivity. In contrast, the stericallydemanding aromatic azido group, in which the resonance is cancelled to some extent, achieves increased distortability, thereby exerting the high reactivity. Not only in the reaction with strained alkyne, but also with simple alkyne such as dimethyl acetylenedicarboxylate (3b), the decrease of distortion energy of doubly sterically-hindered aromatic azido group largely eclipses the steric repulsion between the substrates, thereby, in total, significantly lowers the activation energy. To our knowledge, this is the first report demonstrating the enhanced reactivity of sterically-hindered group by the effect of steric inhibition of resonance. There are some reactions accelerated by the steric assistance, but this is a novel type of steric acceleration in that the intrinsic reactivity of the azido group has been invoked by the steric participation of neighboring groups. This work indicates, though it may sound paradoxical, a possibility of designing a highly reactive functional group by strategically locating it in an appropriate sterically-congested environment.

\section{Methods}

Representative procedure for the double-click reaction. To a solution of diyne 1 $(10.0 \mathrm{mg}, 50.0 \mu \mathrm{mol})$ in $\mathrm{MeOH}(5.00 \mathrm{ml})$ was added a solution of 2,6diisopropylphenyl azide (5c) $(24.4 \mathrm{mg}, 120 \mu \mathrm{mol})$ in $\mathrm{MeOH}(1.25 \mathrm{ml})$ at room temperature. After stirring for $30 \mathrm{~min}$ at the same temperature, the mixture was concentrated under reduced pressure. The residue was purified by flash column chromatography (silica-gel $10 \mathrm{~g}, \mathrm{CH}_{2} \mathrm{Cl}_{2} / \mathrm{MeOH}=100 / 1$ ) to give a mixture of trans$6 \mathrm{c}$ and cis-6c (28.9 mg, $47.6 \mu \mathrm{mol}, 95.4 \%)$. The ratio of trans-6c and cis-6c was determined to be $96 / 4$ based on the ${ }^{1} \mathrm{H}$ NMR analysis. The isomers were separated by flash column chromatography (silica-gel $10 \mathrm{~g}, \mathrm{CH}_{2} \mathrm{Cl}_{2} / \mathrm{MeOH}=100 / 1$ ) and recrystallized. The geometry of each isomers was confirmed by X-ray crystallographical analysis (CCDC 810931 (trans-6c) and CCDC 810838 (cis-6c)).

1. Kolb, H. C., Finn, M. G. \& Sharpless, K. B. Click Chemistry: Diverse Chemical Function from a Few Good Reactions. Angew. Chem. Int. Ed. 40, 2004-2021 (2001).

2. Tornøe, C. W., Christensen, C. \& Meldal, M. Peptidotriazoles on Solid Phase: [1,2,3]-Triazoles by Regiospecific Copper(I)-Catalyzed 1,3-Dipolar Cycloadditions of Terminal Alkynes to Azides. J. Org. Chem. 67, 3057-3064 (2002).

3. Rostovtsev, V. V., Green, L. G., Fokin, V. V. \& Sharpless, K. B. A Stepwise Huisgen Cycloaddition Process: Copper(I)-Catalyzed Regioselective "Ligation" of Azides and Terminal Alkynes. Angew. Chem. Int. Ed. 41, 2596-2599 (2002).

4. Lahann, J. Click Chemistry for Biotechnology and Materials Science, John Wiley \& Sons, West Sussex, 2009.
5. Meldal, M. \& Tornøe, C. W. Cu-Catalyzed Azide-Alkyne Cycloaddition. Chem Rev. 108, 2952-3015 (2008).

6. Wittig, G. \& Krebs, A. Zur Existenz niedergliedriger Cycloalkine, I. Chem. Ber. 94, 3260-3275 (1961).

7. Sletten, E. M. \& Bertozzi, C. R. Bioorthogonal Chemistry: Fishing for Selectivity in a Sea of Functionality. Angew. Chem. Int. Ed. 48, 6974-6998 (2009).

8. Agard, N. J., Prescher, J. A. \& Bertozzi, C. R. A Strain-Promoted [3 + 2] Azide-Alkyne Cycloaddition for Covalent Modification of Biomolecules in Living Systems. J. Am. Chem. Soc. 126, 15046-15047 (2004).

9. Laughlin, S. T., Baskin, J. M., Amacher, S. L. \& Bertozzi, C. R. In Vivo Imaging of Membrane-Associated Glycans in Developing Zebrafish. Science 320, 664-667 (2008).

10. Ning, X., Guo, J. M., Wolfert, A \& Boons, G.-J. Visualizing Metabolically Labeled Glycoconjugates of Living Cells by Copper-Free and Fast Huisgen Cycloadditions. Angew. Chem. Int. Ed. 47, 2253-2255 (2008).

11. Jewett, J. C., Sletten, E. M. \& Bertozzi, C. R. Rapid Cu-Free Click Chemistry with Readily Synthesized Biarylazacyclooctynones. J. Am. Chem. Soc. 132, 3688-3690 (2010).

12. Dommerholt, J. et al. Readily Accessible Bicyclononynes for Bioorthogonal Labeling and Three-Dimensional Imaging of Living Cells. Angew. Chem. Int. Ed. 49, 9422-9425 (2010).

13. Chang, P. V. et al. Copper-free click chemistry in living animals. Proc. Natl. Acad. Sci. U.S.A. 107, 1821-1826 (2010).

14. Debets, M. F., van der Doelen, C. W. J., Rutjes, F. P. J. T. \& van Delft, F. L. Azide: A Unique Dipole for Metal-Free Bioorthogonal Ligations. ChemBioChem, 11, 11681184 (2010).

15. Jewett, J. C. \& Bertozzi, C. R. Cu-free click cycloaddition reactions in chemical biology. Chem. Soc. Rev. 39, 1272-1279 (2010).

16. Wong, H. N. C., Garratt, P. J. \& Sondheimer, F. Unsaturated eight-membered ring compounds. XI. Synthesis of sym-dibenzo-1,5-cyclooctadiene-3,7-diyne and symdibenzo-1,3,5-cyclooctatrien-7-yne, presumably planar conjugated eightmembered ring compounds. J. Am. Chem. Soc. 96, 5604-5605 (1974)

17. Kii, I. et al. Strain-promoted double-click reaction for chemical modification of azido-biomolecules. Org. Biomol. Chem. 8, 4051-4055 (2010).

18. Sanders, B. C. et al. Metal-Free Sequential [3 + 2]-Dipolar Cycloadditions using Cyclooctynes and 1,3-Dipoles of Different Reactivity. J. Am. Chem. Soc. 133, 949957 (2011).

19. Schmidt, M. W. et al. General Atomic and Molecular Electronic Structure System. J. Comput. Chem. 14, 1347-1363 (1993).

20. Böhm, S. \& Exner, O. Steric Inhibition of Resonance: A Revision and Quantitative Estimation on the Basis of Aromatic Carboxylic Acids. Chem. Eur. J. 6, 3391-3398 (2000), and references cited therein.

21. Fleming, I. Molecular Orbitals and Organic Chemical Reactions, John Wiley \& Sons, West Sussex, 2010.

22. Ess, D. H.\& Houk, K. N. Theory of 1,3-Dipolar Cycloadditions: Distortion/ Interaction and Frontier Molecular Orbital Models. J. Am. Chem. Soc. 130, 10187-10198 (2008).

23. Schoenebeck, F., Ess, D. H., Jones, G. O. \& Houk, K. N. Reactivity and Regioselectivity in 1,3-Dipolar Cycloadditions of Azides to Strained Alkynes and Alkenes: A Computational Study. J. Am. Chem. Soc. 131, 8121-8133 (2009).

24. Huisgen, R. 1,3-Dipolar Cycloadditions. Past and Future. Angew. Chem. Int. Ed. Engl. 2, 565-598 (1963).

25. Kwok, S. W., Fotsing, J. R., Fraser, R. J., Rodionov, V. O. \& Fokin, V. V. TransitionMetal-Free Catalytic Synthesis of 1,5-Diaryl-1,2,3-triazoles. Org. Lett. 12, 42174219 (2010).

26. Lobkovsky, E., Bill, E. \& Chirik, P. J. Synthesis and Hydrogenation of Bis(imino)pyridine Iron Imides. J. Am. Chem. Soc. 128, 5302-5303 (2006).

\section{Acknowledgements}

The authors thank Ms. Ayako Hosoya for HRMS analyses. This work was partially supported by a Grant-in-Aid for Scientific Research (22850005) (S.Y.), Suntory Institute for Bioorganic Research (T.H.) and The Naito Foundation (T.H.).

\section{Author contributions}

T.H. directed the study. S.Y. and T.H. conceived the experiment and wrote the paper. A.S and K.K. performed the experiments. S.Y. and T.M. performed computational studies. K.J. and H.U. carried out X-ray structure analyses.

\section{Additional information}

Supplementary information accompanies this paper at http://www.nature.com/ scientificreports

Competing financial interests: The authors declare no competing financial interests License: This work is licensed under a Creative Commons Attribution-NonCommercial-ShareAlike 3.0 Unported License. To view a copy of this license, visit http://creativecommons.org/licenses/by-nc-sa/3.0/

How to cite this article: Yoshida, S. et al. Enhanced clickability of doubly sterically-hindered aryl azides. Sci. Rep. 1, 82; DOI:10.1038/srep00082 (2011). 